J Am Chem Soc. 2016 June 29; 138(25): 7982-7991. doi:10.1021/jacs.6b04018.

\title{
Catalytic Reductive ortho-C-H Silylation of Phenols with Traceless, Versatile Acetal Directing Groups and Synthetic Applications of Dioxasilines
}

\author{
Yuanda Hua§, Parham Asgari§, Thirupataiah Avullala, and Junha Jeon ${ }^{*}$ \\ Department of Chemistry and Biochemistry, University of Texas at Arlington, Arlington, Texas \\ 76019, United States
}

\begin{abstract}
A new, highly selective, bond functionalization strategy, achieved via relay of two transition metal catalysts and the use of traceless acetal directing groups, has been employed to provide facile formation of $\mathrm{C}-\mathrm{Si}$ bonds and concomitant functionalization of a silicon group in a single vessel. Specifically, this approach involves the relay of Ir-catalyzed hydrosilylation of inexpensive and readily available phenyl acetates, exploiting disubstituted silyl synthons to afford silyl acetals and $\mathrm{Rh}$-catalyzed ortho- $\mathrm{C}-\mathrm{H}$ silylation to provide dioxasilines. A subsequent nucleophilic addition to silicon removes the acetal directing groups and directly provides unmasked phenol products and, thus, useful functional groups at silicon achieved in a single vessel. This traceless acetal directing group strategy for catalytic ortho-C-H silylation of phenols was also successfully applied to preparation of multisubstituted arenes. Remarkably, a new formal $a$-chloroacetyl directing group has been developed that allows catalytic reductive $\mathrm{C}-\mathrm{H}$ silylation of sterically hindered phenols. In particular, this new method permits access to highly versatile and nicely differentiated 1,2,3trisubstituted arenes that are difficult to access by other catalytic routes. In addition, the resulting dioxasilines can serve as chromatographically stable halosilane equivalents, which allow not only removal of acetal directing groups but also introduce useful functional groups leading to siliconbridged biaryls. We demonstrated that this catalytic $\mathrm{C}-\mathrm{H}$ bond silylation strategy has powerful synthetic potential by creating direct applications of dioxasilines to other important transformations, examples of which include aryne chemistry, Au-catalyzed direct arylation, sequential orthogonal cross-couplings, and late-stage silylation of phenolic bioactive molecules and BINOL scaffolds.
\end{abstract}

\section{Graphical Abstract}

${ }^{*}$ Corresponding Author: jjeon@uta.edu.

$\S$ Author Contributions

Y.H and P.A. contributed equally to this work.

The authors declare no competing financial interest.

Supporting Information

The following file is available free of charge on the ACS Publications Web site at . The Supporting Information is available free of charge on the ACS Publications website at DOI: 10.1021/jacs.6b04018.

Experimental details and spectroscopic characterization data for all compounds (PDF)

Crystallographic data for compound $\mathbf{4 0}$ (CIF) 


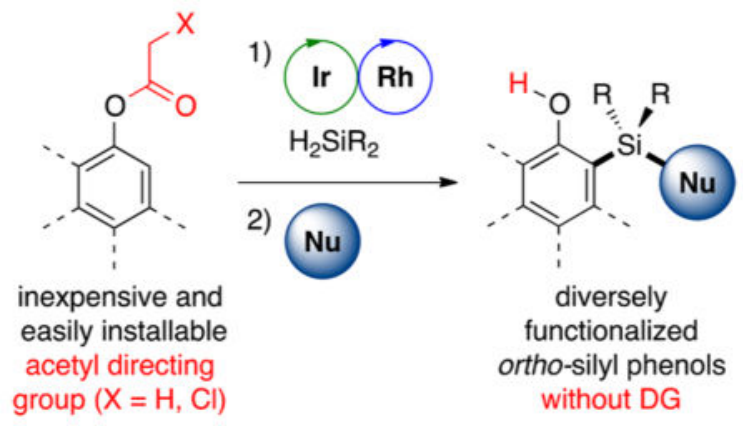

\section{INTRODUCTION}

Interest in organosilane chemistry has increased rapidly in recent years, ${ }^{1}$ including the development of silicon-based materials ${ }^{2}$ and many biomedically relevant agents. ${ }^{1 \mathrm{a}, 3}$ The recent expanding use of these compounds has included their participation in a wide variety of chemical transformations. Such synthetic activities include silicon-based cross-coupling reactions, ${ }^{4}$ oxidations, ${ }^{5}$ silanol hydrogen bond donor catalysts, ${ }^{6}$ and as directing groups for $\mathrm{C}-\mathrm{H}$ functionalization. ${ }^{7}$ In particular, selective silylative functionalization of phenols is important because many bioactive natural products and unnatural congeners, including medicinally important molecules, contain phenolic moieties that contribute to their biological activities. ${ }^{8}$ In light of this fact, there is a fundamental need for the development of more efficient catalytic strategies that provide site-selective access to this motif from readily available precursors. Thus far, several very useful phenol silylation methods have been developed: (1) a sequence of (non)selective bromination, $O$-silylation, and lithium-halogen exchange followed by retro-Brook reactions, ${ }^{9}$ (2) metal-catalyzed silylation of prefunctionalized, protected halophe-nols, ${ }^{10}$ (3) directed ortho-metalation (DoM)/silylation of phenols, ${ }^{11}$ and (4) $\mathrm{KO} t$-Bu-catalyzed silylation of aromatic heterocycles. ${ }^{12}$ These methods offer excellent site selectivity. However, limitations in these systems exist as they generally require a (sub)stoichiometric amount of basic reagents, thereby displaying modest functional group compatibility or involve a limited substrate scope and/or moderate yields.

Significant advances to transition metal-catalyzed selective $\mathrm{C}-\mathrm{H}$ bond functionalizations for preparing structurally diverse, bioactive molecules ${ }^{13}$ have been made through directing group-assisted ${ }^{13 \mathrm{a}, \mathrm{g}, \mathrm{h}, \mathrm{j}, \mathrm{k}, \mathrm{p}, 14}$ or direct ${ }^{13 \mathrm{~d}, \mathrm{f}} \mathrm{C}-\mathrm{H}$ bond activation strategies. Although directing group-assisted $\mathrm{C}-\mathrm{H}$ bond functionalization strategies can achieve the desired transformation with high reactivity and selectivity, directing groups are often difficult to install and manipulate after processes are completed. Additional functional group interconversions, typically involving redox adjustment, are usually carried out under harsh reaction conditions, if indeed removal of the directing group is at all possible. For these limitations to be resolved, strategies for traceless directing group-assisted $\mathrm{C}-\mathrm{H}$ functionalization have been developed..$^{7 \mathrm{a}-\mathrm{d}, 15}$ For instance, Gevorgyan ${ }^{7 \mathrm{a}, \mathrm{b}, 16}$ and $\mathrm{Ge}^{7 \mathrm{c}}$ reported remarkable $\mathrm{C}-\mathrm{H}$ orthoalkenylation, oxygenation, and carboxylation of phenols with silanol traceless directing groups. However, a traceless directing group approach for ortho-C-H silylation has not been reported to date. 
Although diverse catalytic arene dehydrogenative silylations have been developed to prepare valuable organosilanes, ${ }^{17}$ surprisingly, only one example of catalytic ortho-C-H silylation of phenol derivatives has been developed (Hou group, 2011) ${ }^{17 \mathrm{~h}}$ as depicted in Scheme 1a1. Although Hou's pioneering work associated with scandium metallocene-catalyzed directed ortho-silylation of anisoles exhibits excellent site-selectivity despite requiring highly strained, four-membered metallacycle $\mathbf{2}$, it requires excess anisole substrates (10-fold) and has a somewhat limited substrate scope (inaccessible to 1,2,3-trisubstituted arenes $\mathbf{3}$ to $\mathbf{4}$ ). Furthermore, the removal of alkyl masking groups in the presence of silanes is not trivial. Miyaura ${ }^{18}$ and Hartwig ${ }^{19}$ have reported Rh- and Ir-catalyzed steric-controlled meta- or parasilylation of anisoles, respectively (Scheme 1.a2). Whereas Miyaura's Ir-catalyzed silylation required 60 -fold excess of anisole substrates $\mathbf{5}$, the method developed by Hartwig showed broad substrate scope and high site-selectivity, yet the removal of a hydroxyl masking group in the presence of silanes is again questionable.

We recently demonstrated the design and application of a single-pot, catalytic (exhaustive) reductive $\mathrm{C}_{\mathrm{sp} 2}-\mathrm{H}$ and $\mathrm{C}_{\mathrm{sp} 3}-\mathrm{H}$ silylation and silanolization of aromatic carboxylic acid derivatives. ${ }^{20}$ In these studies, we established the mechanism for the hydridosilyl $O, O$-silyl acetal-directed catalytic $\mathrm{C}-\mathrm{H}$ silylation, where the turnover-determining step is an irreversible substrate-metal coordination that proceeds to $\mathrm{C}-\mathrm{H}$ bond cleavage. ${ }^{1 \mathrm{a}, 21} \mathrm{To}$ develop a more general catalytic method to improve arene ortho-C-H silylation of phenols, we have designed a novel approach to sequential catalytic reductive $\mathrm{C}-\mathrm{H}$ silylation. This process centers on postinstallation of other useful moieties on a silicon center that includes spontaneous removal of directing groups by employing versatile silyl acetal directing groups. Hence, we specifically address the aforementioned challenges and limitations in the synthesis of diversely functionalized silyl phenols and significantly expand the versatility of C-H functionalization (Scheme 1b). Herein, we report a single-pot sequential metalcatalyzed reductive ortho- $\mathrm{C}-\mathrm{H}$ silylation of phenols with traceless mixed acetal directing groups, utilizing inexpensive and an easily installable acetyl formal directing group and readily available catalyst and silane. This strategy involves the relay of Ir-catalyzed hydrosilylation of phenyl acetates $\mathbf{8}^{22}$ exploiting disubstituted silyl synthons $\mathbf{7}$ to afford silyl acetals $\mathbf{1 0}$ and $\mathrm{Rh}$-catalyzed $\mathrm{C}-\mathrm{H}$ silylation ${ }^{17 b, c, e, n, q, \mathrm{r}}$ to provide dioxasilines $\mathbf{1 2}$. A subsequent nucleophilic addition to silicon removes the acetal directing groups and provides unmasked phenol products 9 in a single vessel. Importantly, the resulting ortho-silyl phenols $\mathbf{9}$ are useful synthetic vehicles for direct applications to many other important transformations, examples of which include harnessing aryne chemistry, ${ }^{23}$ Au-catalyzed oxidative cross-coupling, ${ }^{4 \mathrm{~d}, \mathrm{e}}$ synthesis of dibenzosiloles, ${ }^{24}$ and catalytic synthesis of a chiral BINOL $^{25}$ scaffold.

\section{RESULTS AND DISCUSSION}

\section{A Single-Pot Catalytic Reductive ortho-C-H Silylation of Phenols with a Traceless Mixed 0,0-Acetal Directing Group}

Prevalent directed $\mathrm{C}-\mathrm{H}$ bond functionalizations proceed through five- or six-membered cyclometalated intermediates. ${ }^{4 a}$ However, our initial concern was that our proposed process conceivably requires rather unfavorable rhodacycloheptane intermediate 11 (Scheme 1b). To 
address this concern, we demonstrated the strategy for traceless, formal acetate directing group-assisted ortho-silylation of phenols (Table 1). Gratifyingly, the single-pot, two-step strategy involving Ir-catalyzed ester hydrosilylation $\left(0.1 \mathrm{~mol} \%\right.$ of $\left.\left.[\mathrm{Ir}(\mathrm{coe}) \mathrm{Cl}]_{2}\right]\right), \mathrm{Rh}-$ catalyzed $\mathrm{C}-\mathrm{H}$ bond silylation using $[\mathrm{Rh}(\mathrm{nbd}) \mathrm{Cl}]_{2}(0.4 \mathrm{~mol} \%)$, and monodentate phosphine $\left.\mathrm{P}(4-\mathrm{MeOPh})_{3}\right)^{17 \mathrm{e}}(2.4 \mathrm{~mol} \%)$ directly produced benzodioxasiline 12a in excellent yield (95\%). A distinctive feature of this mixed $O, O$-acetal-directed Rh-catalyzed $\mathrm{C}-\mathrm{H}$ silylation was essentially complete reaction within 15 min despite the fact that a putative cyclometalated rhodacycloheptane intermediate might be involved.

We then investigated the scope of the single-pot sequential catalytic reductive ortho- $\mathrm{C}-\mathrm{H}$ silylation of phenyl acetates (Table 1). Phenyl acetates bearing a substituent at the ortho position (i.e., methyl, methoxy, fluoro) underwent $\mathrm{C}-\mathrm{H}$ silylation to provide benzodioxasilines (12b-12d) in good yields. The reaction of phenyl acetates possessing a meta substituent (12e-12i) exhibited high site selectivity favoring silylation at less congested $\mathrm{C}-\mathrm{H}$ bonds (>20:1 regioselectivity). $p$-Substituted phenyl acetates holding methyl, $t$-butyl, methoxy, halogens ( $\mathrm{F}$ and $\mathrm{Cl}$ ), trifluoromethyl, silyl blocking group (TBS), and trisubstituted alkene groups were tolerated by the reaction conditions to afford benzodioxasilines $(\mathbf{1 2} \mathbf{j}$ 12q). Interestingly, 4-hydroxyphenyl acetate initially afforded $\mathrm{C}-\mathrm{H}$ silylation product $\mathbf{1 2}$, wherein an unprotected hydroxy group efficiently underwent dehydrogenative silylation with excess diethylsilane followed by hydrosilylation with norbornene (hydrogen acceptor). Reductive $\mathrm{C}-\mathrm{H}$ silylation of both 1-and 2-naphthyl acetates provided single regioisomers (12s and 12t, respectively) with excellent yields. Disubstituted 2,4-dimethylphenyl acetate also generated product $12 \mathrm{u}$ via selective activation of the $\mathrm{C}\left(\mathrm{sp}^{2}\right)-\mathrm{H}$ bond over the $\mathrm{C}\left(\mathrm{sp}^{3}\right)-\mathrm{H}$ bond with good yield (84\%). $\mathrm{C}-\mathrm{H}$ silylation of sesamol acetate afforded the major product $12 \mathbf{v}(4-\mathrm{Si}: 6-\mathrm{Si}=3: 1)$ at the more sterically hindered position. The subsequent nucleophilic ring-opening reactions of resulting 12 with $\mathrm{MeLi}$ in the same vessel afforded ortho-silyl phenols, which allow concomitant removal of the acetal directing group, thereby revealing hydroxy groups. These results clearly establish that the sequence of Ir- and Rh-catalyzed reactions, followed by the ring-opening process, provides a viable catalytic synthesis of ortho-silyl phenols.

\section{Synthesis of Multi-Substituted Arenes}

Catalytic transformation of diacetates or $N$-acetyl acetates into multi-substituted arenes were examined with this $\mathrm{C}-\mathrm{H}$ bond silylation strategy using traceless mixed $O, O$ - and $N, O$-acetal directing groups (Scheme 2). Dual catalytic reductive $\mathrm{C}-\mathrm{H}$ silylation of 1,4-phenylene diacetate $\mathbf{8 x}$, followed by the double-fold ring-opening with MeLi furnished tetra-substituted arene $(\mathbf{9 x})$ in excellent yield (88\%). Furthermore, highly chemo-selective reductive $\mathrm{C}-\mathrm{H}$ silylation/ring-opening of 4-acetox-yphenyl pivolate $\mathbf{8 y}$ to afford trisubstituted arene $(\mathbf{9 y})$ in $72 \%$ yield was observed, as achieved by selective hydrosilylation of acetate over pivolate ( 2 equiv of $\mathrm{H}_{2} \mathrm{SiEt}_{2}$ at rt). However, under dual hydrosilylation conditions (4 equiv of $\mathrm{H}_{2} \mathrm{SiEt}_{2}$ at $60{ }^{\circ} \mathrm{C}$ ) dual $\mathrm{C}-\mathrm{H}$ silylation of $\mathbf{8 y}$ provided tetra-substituted arene (12z) (83\% yield), which underwent ring-opening reaction with $\mathrm{MeLi}$ to give $\mathbf{9 z}$. $\mathrm{N}$-Acetyl-4-indolyl acetate 8aa also tolerated the reaction conditions to provide dual $\mathrm{C}-\mathrm{H}$ silylation product 12aa via formation of the intermediate containing mixed $O, O$ - and $N, O$-silyl acetals (not shown). Upon treatment with MeLi, 9aa was generated in $38 \%$ yield over three steps. Several 
conditions were employed in an attempt to remove the hemiaminal group; however, protodesilylation (at C-5) was observed under most reaction conditions studied. Notably, when para-acetamide-substituted phenyl acetate (i.e., $O$-acetyl acetaminophen) was subjected to the hydrosilylation conditions mixed $O, O$-silyl acetal, with concomitant reduction of amide to secondary silyl amine, initially formed, which subsequently underwent $\mathrm{C}-\mathrm{H}$ silylation to provide 12ab after pivalation of the amine. Subsequent treatment with MeLi afforded trisubstituted arene $\mathbf{9 a b}$.

\section{Dioxasilines as Halosilane Equivalents for Synthesis of Functionalized Silanes}

Organosilanes and organosilanols have been utilized for their unique biological functions and biomedically relevant agents. ${ }^{3,26}$ Although advances have been achieved, syntheses of diverse silanes by catalytic means remain significantly limited. For example, Brookhart reported only two synthetically useful silanes $\left(\mathrm{Et}_{2} \mathrm{SiH}_{2}\right.$ and $\left.\mathrm{PhMeSiH}_{2}\right)$ for Ir-catalyzed ester hydrosilylation. ${ }^{22 f}$ Furthermore, a stoichiometric method for synthesis of functionalized phenolic silanes 15, involving (non)selective bromination/retro-Brook reactions, requires substantial effort (i.e., preparation of chloroarylsilanes $\mathbf{1 4}$ bearing various aryl moieties), and the overall yield is unknown (Scheme 3a). ${ }^{9 b}$ Alternatively, directed ortho-metalation (DoM)/ silylation of phenols ${ }^{11}$ also has limitations imposed by the generation of chromatographically unstable chlorosilanes $\mathbf{1 7}$ and a difficult directing group removal step associated with facile protodesilylation (Scheme $3 b$ ). To improve this limited silane scope and thereby prepare diversely functionalized silanes, we investigated sequential catalytic $\mathrm{C}-$ $\mathrm{H}$ silylation coupled with nucleophilic ring-opening reactions of "dioxasilines as stable halosilane equivalents" that readily incorporate a variety of motifs (Scheme 3c). Advantages of this method would be 2-fold: first, it provides a postintroduction of silyl substituents containing useful functional groups, which may be not compatible with an Ir/Rh-catalytic cascade; second, it eliminates the need to prepare a variety of not readily available dihydrosilanes for hydrosilylation. Therefore, we explored an array of nucleophiles: hydride (lithium aluminum hydride) (to 9ac), carbon nucleophiles [MeLi (or MeMgBr)] (to 9a), nBuLi (to 9ad), $\mathrm{PhLi}$ (or PhMgBr) (to 9ae), vinyl magnesium chloride (to 9af), allyl magnesium chloride (to 9ag), lithium trimethylsilyl acetylide (to 9ah), heteroaryl lithium reagents (to 2-silyl furan 9ai, 2-silyl benzofuran 9aj, 2-thiofuran 9ak, 2-silyl benzothiofuran 9al, and 2-silyl indole 9am), and oxygen nucleophiles (lithium mentholate) (to 9an). All of these nucleophiles afforded excellent to good yields of the corresponding silyl phenols.

\section{Synthesis of 1,2,3-Trisubstituted Arenes via Catalytic Reductive C-H Silylation}

On the basis of the wide substrate scope presented in Table 1, we investigated the potential of catalytic reductive ortho-C-H silylation of phenols directed by silyl acetal. However, we encountered a problem during our investigation of the substrate scope of ortho- $\mathrm{C}-\mathrm{H}$ silylation of sterically hindered phenols. Surprisingly, minor steric variation on a substrate, such as 8-Et (cf. 8-Me), drastically hindered the hydrosilylation (Scheme 4a). The Hou group also observed similar reactivity; in fact, they observed even more sensitivity to the sterics with Sc-catalyzed arene ortho-silylation, where even ortho-methyl anisole did not react (see 3 to 4 in Scheme 1a1). ${ }^{17 h}$ Of note, efficient catalytic synthesis of 1,2,3trisubtituted arenes are not trivial owing to the necessity of high reactivity over steric 
hindrance and high regioselectivity. Although A-values of methyl and ethyl are fairly similar (1.7 vs $1.75 \mathrm{kcal} / \mathrm{mol}$, respectively), ${ }^{27}$ it is speculated that the population of reactive conformers by rotation perhaps dictates this unusual reactivity difference. To overcome this obstacle, we explored the development of other efficient traceless directing groups (Scheme 4b). Brookhart proposed that the turnover-limiting step of Ir-catalyzed hydrosilylation would be the transfer of silylium ions $\left(\mathrm{R}_{2} \mathrm{HSi}^{+}\right)$to the carbonyl oxygen of esters. ${ }^{22 f, 28} \mathrm{We}$ speculated that effective recruiting of iridium silyl hydride species to esters could be a crucial factor for hindered esters (18 to 19). In addition, the electron-withdrawing $X$ atom (group) could facilitate Ir-mediated hydride transfer to carbonyl (19 to 20). Therefore, to transfer the silylium ions to carbonyl and succeed in achieving iridium hydride more easily, we designed and examined an $a$-heteroatom-containing acetyl formal directing group as a bidentate chelating moiety (e.g., an $a$-fluoro, chloro, bromo, and methoxy acetyl) to metal (Scheme 4c). We found that $a$-chloroacetate was among the most effective formal directing groups. This method was expanded to more sterically demanding ortho-substituted substrates. Remarkably, the phenyl $\boldsymbol{a}$-chloroacetate smoothly underwent sequential hydrosilylation/C-H silylation of substrates bearing ortho-isopropyl, tert-butyl, and phenyl moieties (Scheme 4d). These are surprising results because only a few successful chelationcontrolled nucleophilic additions to $a$-halo carbonyl or imino electrophiles have been reported owing to the relatively low basicity of halogens, and all of these prior examples utilized $\boldsymbol{a}$-fluoro carbonyl derivatives. ${ }^{29}$ Although the Walsh group demonstrated diastereoselective chelation-controlled addition of carbon nucleophiles to $a$-chloro aldimines, transition metal-catalyzed chelation-controlled hydrosilylation of $a$-chloroesters has not previously been described. ${ }^{30}$

\section{Synthetic Applications of Benzodioxasilines}

A major aspect of this work is to introduce a novel strategy to catalytic ortho-C-H silylation via sequential $\mathrm{C}-\mathrm{H}$ silylation post-installation of other useful moieties on a silicon center. This approach permits spontaneous removal of a directing group and simultaneously addresses the challenges of synthesis of diversely functionalized unmasked ortho-silyl phenols 9 (Scheme 3). We further explored the powerful synthetic utilities of catalytically generated ortho-silyl phenols to other important transformations (Scheme 5).

\section{Aryne Cycloaddition of ortho-Silyl Triflates and Halo and Boro ipso-Desilylations}

1,2-Silyl triflates are versatile motifs for a variety of areas in organic synthesis. Our catalytic ortho-silylation method permits access to 1,2-diethylmethylsilyl triflates $\mathbf{2 2}$ containing a variety of substituents in an extremely straightforward fashion. Some such substrates were previously difficult to prepare owing to functional group incompatibility or electronic bias. We demonstrated aryne-furan cycloaddition that produced 23a-c in good yields (Scheme 5). ${ }^{23}$ In addition, benzodioxasiline $\mathbf{1 2}$ could easily undergo iodo- and boro-induced ipsodesilylations to generate $\mathbf{2 4}$ and $\mathbf{2 5}$ in good yields, respectively (Scheme 5).

\section{Pd-Catalyzed Hiyama-Denmark Cross-Coupling}

The biaryl scaffold is prevalent in biologically active molecules and is a ubiquitous functional motif in medicine. ${ }^{31}$ The Hiyama-Denmark cross-coupling, using nontoxic aryl 
silanes, is among the most versatile catalytic method for biaryl synthesis. ${ }^{4 a-c}$ Nonetheless, this strategy suffers from the requirements for aryl halide sources in the $\mathrm{C}-\mathrm{C}$ bond-forming reaction and basic conditions for activating silanes. When attempting Pd-catalyzed HiyamaDenmark cross-coupling of benzodisiloxane 12a, we observed product 26a in low to moderate yields (3-50\%) along with significant protodesilylation byproduct 28a (Table 2). On the basis of our literature survey, the efficiency of silicon-based cross-coupling of sterically encumbered ortho-substituted silanes (or siloxanes) with corresponding haloarene cross-coupling partners has been generally poor. ${ }^{32}$

\section{Au-Catalyzed Oxidative Direct Arylation of Aryl Silanes}

A direct alternative to the Hiyama-Denmark cross-coupling would be the oxidative direct cross-coupling of aryl silanes with simple arenes as a partner, ${ }^{13 c, f, j, 33}$ as recently reported by Lloyd-Jones and Russel. ${ }^{4 \mathrm{~d}, \mathrm{e}}$ This strategy is, however, underexploited in 2-silyl triflates derived from dioxasilines as oxidative direct coupling partners (Scheme 6). Our developed reductive $\mathrm{C}-\mathrm{H}$ silylation strategy would enable the rapid preparation of such triflatecontaining partners for the silane-based oxidative direct coupling. Gratifyingly, gold(I)catalyzed oxidative cross-coupling of 1,2-silyl triflates $\mathbf{2 2}$ with nonprefunctionalized arenes afforded biaryls $\mathbf{2 7}$ in moderate to excellent yields (Scheme 6). With brief optimization, the Au-catalyzed silane-based oxidative cross-coupling directly provided biaryls $\mathbf{2 7} \mathbf{a}-\mathbf{j}$ holding useful functional groups and moieties (e.g., triflate, mesylate, ester, bromide, chloride, fluoride, furan, and thiopene). These functional groups are useful for subsequent downstream reactions such as other metal-catalyzed cross-couplings.

\section{Orthogonal Cross-Coupling}

The Au-catalyzed oxidative cross-coupling of biaryls $\mathbf{2 7} \mathbf{a}$ and $\mathbf{2 7} \mathbf{c}-\mathbf{j}$ bearing triflate groups can be used for subsequent cross-coupling reactions. Examples include Suzuki crosscoupling of 27e with phenyl boronic acid to generate 1,2-diaryl benzene 29 (94\%) (Scheme 7a) and Heck reaction of $\mathbf{2 7} \mathbf{c}$ with 2-methylstyrene to furnish 1,1-disubstituted alkene $\mathbf{3 0}$ (61\%) (Scheme 7b).

\section{Late-Stage Functionalization of Phenol-Containing Bioactive Molecules Estrone and Estradiol}

We explored the synthetic utility of the catalytic reductive acetal directing group-assisted ortho-C-H silylation of phenols in known bioactive molecules (Scheme 8). We again exhibited that $a$-chloroacetyl-derived silyl acetal was crucial to afford ester hydrosilylation/C-H bond silylation (only $\mathrm{C} 2$ position) of estrone to provide $32 \mathbf{b}$ ( $88 \%$ yield) (the parent acetyl directing group only afforded 32a in 30\% yield), presumably due to remote steric influence (Scheme 8a). Ring-opening of $\mathbf{3 2} \mathbf{b}$ by vinyl lithium furnished $\mathbf{3 3}$ $\left(80 \%\right.$ yield). ${ }^{7 \mathrm{a}, 16,34}$ Unfortunately, we were unable to remove the ketal protecting group within $\mathbf{3 3}$ under a variety of reaction conditions due to concomitant protodesilylation of C2silane. ${ }^{34}$ We then studied a more direct method involving late-stage functionalization of estradiol 35 (Scheme 8b). A four-step sequence involving bis-chloroacetylation, reductive $\mathrm{C}-\mathrm{H}$ silylation, and vinyl addition directly permits $\mathrm{C} 2$-silyl estradiol 37 (via 36) without protecting group manipulation. 


\section{Catalytic Synthesis of 3,3'-Bissilyl BINOL Using a Traceless Acetal Directing Group}

Lastly, we examined whether this catalytic silylation method is applicable to preparation of 3,3'-bis-silylation of binaphthol (BINOL), which has been extensively utilized for asymmetric catalysis. 3,3'-Bis-silyl BINOL $\mathbf{4 0}$ was synthesized from rac-BINOL in high yield in a four step operation-of note, only one enantiomer of the BINOL racemic mixture is presented in Scheme 9. Overall, our development of a strategy for late-stage modification enables synthesis of structurally unique bioactive molecules and chiral scaffolds in a rapid and highly site-selective manner and obviates a stepwise, multistep synthesis, which would be difficult through the existing catalytic ortho-C-H silylation. ${ }^{17 \mathrm{~h}}$

\section{CONCLUSIONS}

A new strategy employing disubstituted silyl synthons and phenyl acetates for a single-pot sequential metal-mediated catalytic reductive $\mathrm{C}-\mathrm{H}$ silylation of phenols with traceless acetal directing groups has been successfully achieved. The relay of Ir-catalyzed hydrosilylation of phenyl acetates and $\mathrm{Rh}$-catalyzed $\mathrm{C}-\mathrm{H}$ silylation provides dioxasilines. A subsequent nucleophilic addition of diverse nucleophiles to dioxasilines serving as halosilane equivalents not only readily incorporates a variety of functional moieties but also concomitantly removes the acetal directing groups in a single vessel. To resolve synthetic challenges of 1,2,3-trisubstituted, hindered arenes, we developed a new $a$-chloroacetyl formal directing group that allows catalytic reductive ortho- $\mathrm{C}-\mathrm{H}$ silylation of sterically hindered phenols. We also demonstrated several important downstream reactions of the resulting 1,2-silyl phenols, including Au-catalyzed oxidative direct cross-coupling, aryne cycloaddition chemistry, and late-stage silylation of phenolic bioactive molecules and BINOL scaffold, exploiting the traceless acetal directing group strategy to afford C2-silyl estrone, C2-silyl estradiol, and 3,3' -bis-silyl BINOL.

\section{EXPERIMENTAL SECTION}

\section{General Experimental Information}

Reactions requiring anhydrous conditions were performed under an atmosphere of nitrogen or argon in flame- or oven-dried glassware. Anhydrous toluene and dichloromethane (DCM) were distilled from $\mathrm{CaH}_{2}$. Anhydrous tetrahydrofuran (THF) and diethyl ether $\left(\mathrm{Et}_{2} \mathrm{O}\right)$ were distilled from sodium and benzophenone. Triethylamine and pyridine were distilled from KOH. DMF and DMSO were stored over $4 \AA$ molecular sieves. All other solvents and reagents from commercial sources were used as received. NMR spectra were recorded on a 500 or $300 \mathrm{MHz}$ NMR spectrometer. ${ }^{1} \mathrm{H}$ NMR chemical shifts are referenced to chloroform (7.26 ppm) and DMSO- $d_{6}(2.50 \mathrm{ppm}) .{ }^{13} \mathrm{C}$ NMR chemical shifts are referenced to ${ }^{13} \mathrm{CDCl}_{3}$ $(77.23 \mathrm{ppm})$ and DMSO- $d_{6}(39.52 \mathrm{ppm})$. The following abbreviations are used to describe multiplets: s (singlet), d (doublet), t (triplet), q (quartet), pent (pentet), m (multiplet), nfom (nonfirst-order multiplet), and br (broad). The following format was used to report peaks: chemical shift in ppm [multiplicity, coupling constant(s) in $\mathrm{Hz}$, integral, and assignment]. ${ }^{1} \mathrm{H}$ NMR assignments are indicated by structure environment, e.g., $\mathrm{CH}_{\mathrm{a}} \mathrm{H}_{\mathrm{b}} \cdot{ }^{1} \mathrm{H} \mathrm{NMR}$ and ${ }^{13} \mathrm{C}$ NMR were processed with the iNMR software program. Infrared (IR) spectra were recorded using neat (for liquid compound) or a thin film from a concentrated DCM solution.

J Am Chem Soc. Author manuscript; available in PMC 2016 November 10. 
Absorptions are reported in $\mathrm{cm}^{-1}$. Only the most intense and/or diagnostic peaks are reported. MPLC refers to medium pressure liquid chromatography (25-200 psi) using handpacked columns of silica gel (20-45 $\mu \mathrm{m}$, spherical, $70 \AA$ A pore size), an HPLC pump, and a differential refractive index detector. High-resolution mass spectra (HRMS) were recorded in electrospray ionization time-of-flight (ESI-TOF) mode. Samples were introduced as mixed solutions of methanol and methylene chloride (DCM). GC-MS experiments using electron impact ionization (EI) were performed at $70 \mathrm{eV}$ using a mass-selective detector. Analytical TLC experiments were performed on F254 plates with $250 \mu \mathrm{m}$ thickness. Detection was performed by UV light or potassium phosphomolybdic acid, permanganate, or $p$-anisaldehyde staining.

\section{General Procedure for Ir-Catalyzed Reductive Ester Silylation-Preparation of Silyl Acetals (10)}

$\left[\operatorname{Ir}(\mathrm{coe}){ }_{2} \mathrm{Cl}\right]_{2}(0.9 \mathrm{mg}, 0.1 \mathrm{~mol} \%)$ and aryl acetates $\mathbf{8}(1 \mathrm{mmol})$ were added to a flame-dried, nitrogen-purged septum-capped vial. The mixture was dissolved with THF ( $0.3 \mathrm{~mL}, 3.3 \mathrm{M})$, and diethylsilane $(0.26 \mathrm{~mL}, 2 \mathrm{mmol})$ was added to the mixture. The septum on the vial was replaced by a screw cap with a Teflon liner under a $\mathrm{N}_{2}$ atmosphere [note: diethylsilane (bp of $56^{\circ} \mathrm{C}$ and density of $0.686 \mathrm{~g} / \mathrm{mL}$ ) is volatile]. The reaction mixture was stirred for $3-12 \mathrm{~h}$ at $60{ }^{\circ} \mathrm{C}$. Volatiles were removed in vacuo to afford silyl acetals $\mathbf{1 0}$, which were directly used for subsequent reactions without further purification.

\section{General Procedure for Rh-Catalyzed Arene ortho-C-H Silylation of Hydridodiethylsilyl Acetals-Preparation of Benzodioxasilines (12)}

$\left[\mathrm{Rh}(\mathrm{nbd}) \mathrm{Cl}_{2}\right.$ (1.84 mg, $\left.0.4 \mathrm{~mol} \%\right)$, tris(4-methoxyphenyl)phosphine ( $8.45 \mathrm{mg}, 2.4 \mathrm{~mol} \%$ ), norbornene $(188 \mathrm{mg}, 2 \mathrm{mmol})$, and THF ( $1 \mathrm{~mL}, 1 \mathrm{M})$ were added to the crude silyl acetals 10 ( $1 \mathrm{mmol})$. The septum on the vial was replaced by a screw cap with a Teflon liner, and the mixture was stirred at $120^{\circ} \mathrm{C}$ for 15 min (unless otherwise mentioned in Table 1).

Reaction progress was monitored by GC-MS spectrometry. The resulting benzodioxasi-lines 12 were directly used for a subsequent reaction without further purification. For analytical purposes, volatiles were removed in vacuo, and the resulting mixture was dissolved with pentane, filtered through a pad of Celite, and concentrated in vacuo. The crude product was purified by MPLC (hexanes/EtOAc $=80: 1,5 \mathrm{~mL} / \mathrm{min}$, retention time of 5-15 $\mathrm{min}$ ).

\section{General Procedure for Nucleophile Opening of Benzodioxasiline-Preparation of 2- Silylphenol (9)}

The crude benzodioxasilines $12(1 \mathrm{mmol}$ in THF, $1 \mathrm{M})$ were diluted with THF $(1 \mathrm{~mL}, 0.5$ M) and cooled to $-78{ }^{\circ} \mathrm{C}$; then, nucleophiles ( 3 equiv) were added to the reaction mixture and stirred at $-78{ }^{\circ} \mathrm{C}$ for $30 \mathrm{~min}$. The reaction was quenched at $-78{ }^{\circ} \mathrm{C}$ by adding saturated aqueous ammonium chloride solution; then, the mixture was acidified to $\mathrm{pH} \sim 4-5$ with aqueous $\mathrm{HCl}(1 \mathrm{M})$. The mixture was extracted with diethyl ether. The combined organic layer was washed with water and brine and dried over anhydrous sodium sulfate. Volatiles were removed in vacuo, and the crude mixture was purified by MPLC to afford 2-silyl phenols 9 (hexanes/EtOAc $=20: 1,5 \mathrm{~mL} / \mathrm{min}$, retention time of 6-20 min). 


\section{Supplementary Material}

Refer to Web version on PubMed Central for supplementary material.

\section{Acknowledgments}

This work is also supported by the ACS Petroleum Research Fund (PRF\# 54831-DNI1), National Institutes of Health (NIH) (GM116031), and start-up funds provided by the University of Texas Arlington. The NSF (CHE-0234811 and CHE-0840509) is acknowledged for partial funding of the purchases of the NMR spectrometers used in this work.

\section{References}

1. (a) Ojima, ILZ.; Zhu, J. Recent Advances in the Hydrosilylation and Related Reactions. In: Rappoport, Z.; Apeloig, Y., editors. The Chemistry of Organic Silicon Compounds. Vol. 2. Wiley; Chichester, U.K: 1998. p. 1687-1792.(b) Tacke, R.; Wagner, SA. Chirality in Bioorganosilicon Chemistry. In: Rappoport, Z.; Apeloig, Y., editors. The Chemistry of Organic Silicon Compounds. Vol. 2. Wiley; Chichester, U.K: 1998. p. 2363-2400.(c) Chandrasekhar V, Boomishankar R, Nagendran S. Chem Rev. 2004; 104:5847-5910. [PubMed: 15584691] (d) Jeon M, Han J, Park J. ACS Catal. 2012; 2:1539-1549.

2. (a) Rochow, EG. Silicon and silicones. Springer; New York: 1987. (b) Miller RD, Michl J. Chem Rev. 1989; 89:1359-1410.(c) Murugavel R, Voigt A, Walawalkar MG, Roesky HW. Chem Rev. 1996; 96:2205-2236. [PubMed: 11848826]

3. (a) Nielsen L, Lindsay KB, Faber J, Nielsen NC, Skrydstrup T. J Org Chem. 2007; 72:10035-10044. [PubMed: 18001103] (b) Franz AK, Wilson SO. J Med Chem. 2013; 56:388-405. [PubMed: 23061607] (c) Mutahi, Mw; Nittoli, T.; Guo, L.; Sieburth, SM. J Am Chem Soc. 2002; 124:73637375. [PubMed: 12071745]

4. (a) Denmark, SE.; Sweis, RF. In Metal-Catalyzed Cross-Coupling Reactions. de Meijere, A.; Diederich, F., editors. Vol. Chapter 4. Wiley-VCH; New York: 2004. (b) Denmark SE, Regens CS. Acc Chem Res. 2008; 41:1486-1499. [PubMed: 18681465] (c) Nakao Y, Hiyama T. Chem Soc Rev. 2011; 40:4893-4901. [PubMed: 21755089] (d) Ball LT, Lloyd-Jones GC, Russell CA. Science. 2012; 337:1644-1648. [PubMed: 23019647] (e) Ball LT, Lloyd-Jones GC, Russell CA. J Am Chem Soc. 2014; 136:254-264. [PubMed: 24367895]

5. Jones GR, Landais Y. Tetrahedron. 1996; 52:7599-7662.

6. (a) Özçubukçu S, Schmidt F, Bolm C. Org Lett. 2005; 7:1407-1409. [PubMed: 15787518] (b) Schafer AG, Wieting JM, Mattson AE. Org Lett. 2011; 13:5228-5231. [PubMed: 21894881] (c) Tran NT, Wilson SO, Franz AK. Org Lett. 2012; 14:186-189. [PubMed: 22148869]

7. (a) Huang C, Chattopadhyay B, Gevorgyan V. J Am Chem Soc. 2011; 133:12406-12409. [PubMed: 21766826] (b) Huang C, Ghavtadze N, Chattopadhyay B, Gevorgyan V. J Am Chem Soc. 2011; 133:17630-17633. [PubMed: 21999512] (c) Wang C, Ge H. Chem - Eur J. 2011; 17:14371-14374. [PubMed: 22095863] (d) Huang C, Ghavtadze N, Godoi B, Gevorgyan V. Chem - Eur J. 2012; 18:9789-9792. [PubMed: 22847834] (e) Ghavtadze N, Melkonyan FS, Gulevich AV, Huang C, Gevorgyan V. Nat Chem. 2014; 6:122-125. [PubMed: 24451587]

8. (a) Carlsson A, Lindqvist M, Magnusson T. Nature. 1957; 180:1200.(b) O’Brien I, Cox G, Gibson F. Biochim Biophys Acta, Gen Subj. 1970; 201:453-460.(c) Kaldor SW, Kalish VJ, Davies JF, Shetty BV, Fritz JE, Appelt K, Burgess JA, Campanale KM, Chirgadze NY, Clawson DK, Dressman BA, Hatch SD, Khalil DA, Kosa MB, Lubbehusen PP, Muesing MA, Patick AK, Reich SH, Su KS, Tatlock JH. J Med Chem. 1997; 40:3979-3985. [PubMed: 9397180] (d) Pereira DM, Valentão P, Pereira JA, Andrade PB. Molecules. 2009; 14:2202-2211.

9. (a) Frye CL, Salinger RM, Fearon F, Klosowski J, DeYoung T. J Org Chem. 1970; 35:1308-1314. (b) Shimizu M, Mochida K, Hiyama T. Angew Chem, Int Ed. 2008; 47:9760-9764.

10. (a) Denmark SE, Kallemeyn JM. Org Lett. 2003; 5:3483-3486. [PubMed: 12967305] (b) Denmark SE, Smith RC, Chang WTT, Muhuhi JM. J Am Chem Soc. 2009; 131:3104-3118. [PubMed: 19199785] 
11. (a) Whisler MC, MacNeil S, Snieckus V, Beak P. Angew Chem, Int Ed. 2004; 43:2206-2225.(b) Wilson SO, Tran NT, Franz AK. Organometallics. 2012; 31:6715-6718.

12. Toutov AA, Liu WB, Betz KN, Fedorov A, Stoltz BM, Grubbs RH. Nature. 2015; 518:80-84. [PubMed: 25652999]

13. (a) Dick AR, Sanford MS. Tetrahedron. 2006; 62:2439-2463.(b) Godula K, Sames D. Science. 2006; 312:67-72. [PubMed: 16601184] (c) Alberico D, Scott ME, Lautens M. Chem Rev. 2007; 107:174-238. [PubMed: 17212475] (d) Seregin IV, Gevorgyan V. Chem Soc Rev. 2007; 36:11731193. [PubMed: 17576484] (e) Davies HM, Manning JR. Nature. 2008; 451:417-424. [PubMed: 18216847] (f) Ackermann L, Vicente Rn, Kapdi AR. Angew Chem, Int Ed. 2009; 48:9792-9826. (g) Chen X, Engle KM, Wang DH, Yu JQ. Angew Chem, Int Ed. 2009; 48:5094-5115.(h) Daugulis O, Do HQ, Shabashov D. Acc Chem Res. 2009; 42:1074-1086. [PubMed: 19552413] (i) Ishihara Y, Baran PS. Synlett. 2010; 2010:1733-1745.(j) Lyons TW, Sanford MS. Chem Rev. 2010; 110:1147-1169. [PubMed: 20078038] (k) Sun CL, Li BJ, Shi ZJ. Chem Commun. 2010; 46:677-685.(1) Gutekunst WR, Baran PS. Chem Soc Rev. 2011; 40:1976-1991. [PubMed: 21298176] (m) McMurray L, O’Hara F, Gaunt MJ. Chem Soc Rev. 2011; 40:1885-1898. [PubMed: 21390391] (n) Neufeldt SR, Sanford MS. Acc Chem Res. 2012; 45:936-946. [PubMed: 22554114] (o) Yamaguchi J, Yamaguchi AD, Itami K. Angew Chem, Int Ed. 2012; 51:8960-9009. (p) Ackermann L. Acc Chem Res. 2014; 47:281-295. [PubMed: 23379589]

14. Colby DA, Bergman RG, Ellman JA. Chem Rev. 2010; 110:624-655. [PubMed: 19438203]

15. (a) García-Rubia A, Urones B, Gómez Arrayás R, Carretero JC. Chem - Eur J. 2010; 16:96769685. [PubMed: 20652913] (b) Cornella J, Righi M, Larrosa I. Angew Chem, Int Ed. 2011; 50:9429-9432.(c) Dai H, Stepan A, Plummer M, Zhang Y, Yu J. J Am Chem Soc. 2011; 133:7222-7228. [PubMed: 21488638] (d) Richter H, Beckendorf S, Mancheño OG. Adv Synth Catal. 2011; 353:295-302.(e) Rousseau G, Breit B. Angew Chem, Int Ed. 2011; 50:2450-2494.(f) Yu M, Liang Z, Wang Y, Zhang Y. J Org Chem. 2011; 76:4987-4994. [PubMed: 21545111] (g) Wang C, Chen H, Wang Z, Chen J, Huang Y. Angew Chem, Int Ed. 2012; 51:7242-7245.

16. Wang Y, Gevorgyan V. Angew Chem, Int Ed. 2015; 54:2255-2259.

17. (a) Djurovich PI, Dolich AR, Berry DH. J Chem Soc, Chem Commun. 1994:1897-1898.(b) Ezbiansky K, Djurovich PI, LaForest M, Sinning DJ, Zayes R, Berry DH. Organometallics. 1998; 17:1455-1457.(c) Sakakura T, Tokunaga Y, Sodeyama T, Tanaka M. Chem Lett. 1987:2375-2378. (d) Tobisu M, Ano Y, Chatani N. Chem - Asian J. 2008; 3:1585-1591. [PubMed: 18494014] (e) Ureshino T, Yoshida T, Kuninobu Y, Takai K. J Am Chem Soc. 2010; 132:14324-14326. [PubMed: 20866053] (f) Furukawa S, Kobayashi J, Kawashima T. Dalton Trans. 2010; 39:9329_ 9336. [PubMed: 20830392] (g) Simmons EM, Hartwig JF. J Am Chem Soc. 2010; 132:1709217095. [PubMed: 21077625] (h) Oyamada J, Nishiura M, Hou Z. Angew Chem, Int Ed. 2011; 50:10720-10723.(i) Klare HF, Oestreich M, Ito J-i, Nishiyama H, Ohki Y, Tatsumi K. J Am Chem Soc. 2011; 133:3312-3315. [PubMed: 21341748] (j) Tobisu M, Hasegawa J, Kita Y, Kinuta H, Chatani N. Chem Commun. 2012; 48:11437-11439.(k) Mita T, Michigami K, Sato Y. Org Lett. 2012; 14:3462-3465. [PubMed: 22712564] (1) Kuznetsov A, Gevorgyan V. Org Lett. 2012; 14:914-917. [PubMed: 22272663] (m) Sakurai T, Matsuoka Y, Hanataka T, Fukuyama N, Namikoshi T, Watanabe S, Murata M. Chem Lett. 2012; 41:374-376.(n) Kuninobu Y, Yamauchi K, Tamura N, Seiki T, Takai K. Angew Chem. 2013; 125:1560-1562.(o) Kuninobu Y, Nakahara T, Takeshima H, Takai K. Org Lett. 2013; 15:426-428. [PubMed: 23305172] (p) Li Q, Driess M, Hartwig JF. Angew Chem, Int Ed. 2014; 53:8471-8474.(q) Cheng C, Hartwig JF. Science. 2014; 343:853-857. [PubMed: 24558154] (r) Cheng C, Hartwig JF. J Am Chem Soc. 2014; 136:1206412072. [PubMed: 25082802] (s) Cheng C, Hartwig JF. Chem Rev. 2015; 115:8946-8975. [PubMed: 25714857]

18. Ishiyama T, Sato K, Nishio Y, Miyaura N. Angew Chem, Int Ed. 2003; 42:5346-5348.

19. Cheng C, Hartwig JF. J Am Chem Soc. 2015; 137:592-595. [PubMed: 25514197]

20. (a) Hua Y, Jung S, Roh J, Jeon J. J Org Chem. 2015; 80:4661-4671. [PubMed: 25853682] (b) Hua Y, Asgari P, Dakarapu US, Jeon J. Chem Commun. 2015; 51:3778-3781.

21. Simmons EM, Hartwig JF. Angew Chem, Int Ed. 2012; 51:3066-3072.

22. (a) Parks DJ, Piers WE. J Am Chem Soc. 1996; 118:9440-9441.(b) Parks DJ, Blackwell JM, Piers WE. J Org Chem. 2000; 65:3090-3098. [PubMed: 10814201] (c) Igarashi M, Mizuno R, Fuchikami T. Tetrahedron Lett. 2001; 42:2149-2151.(d) Nakanishi J, Tatamidani H, Fukumoto Y, 
Chatani N. Synlett. 2006; 2006:869-872.(e) Maciejewski, H.; Pietraszuk, C.; Pawluc, P.; Marciniec, B. Advances in Silicon Science. Vol. 1. Springer; Berlin: 2009. In Hydrosilylation: A Comprehensive Review On Recent Advances. (f) Cheng C, Brookhart M. Angew Chem, Int Ed. 2012; 51:9422-9424.

23. (a) Roberts JD, Simmons HE, Carlsmith LA, Vaughan CW. J Am Chem Soc. 1953; 75:3290-3291. (b) Wenk HH, Winkler M, Sander W. Angew Chem, Int Ed. 2003; 42:502-528.(c) Gampe C, Carreira E. Angew Chem, Int Ed. 2012; 51:3766-78.(d) Hoye TR, Baire B, Niu D, Willoughby PH, Woods BP. Nature. 2012; 490:208-212. [PubMed: 23060191] (e) Tadross PM, Stoltz BM. Chem Rev. 2012; 112:3550-3577. [PubMed: 22443517] (f) Goetz AE, Garg NK. J Org Chem. 2014; 79:846-851. [PubMed: 24410270]

24. (a) Yamaguchi S, Tamao K. J Organomet Chem. 2002; 653:223-228.(b) Hissler M, Dyer PW, Réau R. Coord Chem Rev. 2003; 244:1-44.

25. (a) Brunel JM. Chem Rev. 2005; 105:857-898. [PubMed: 15755079] (b) Kampen D, Reisinger C, List B. Top Curr Chem. 2010; 291:395-456. [PubMed: 21494945]

26. Ojima, I.; Li, Z.; Zhu, J. The Hydrosilylation Reaction. In: Patai, S.; Rappoport, Z., editors. The Chemistry of Organic Silicon Compounds. Vol. 1. Wiley; Chichester, U.K: 1989. p. 1479-1526.

27. (a) Eliel EL, Satici H. J Org Chem. 1994; 59:688-689.(b) Marzabadi C, Anderson J, GonzalezOuteirino J, Gaffney P, White C, Tocher D, Todaro L. J Am Chem Soc. 2003; 125:15163-73. [PubMed: 14653751]

28. (a) Park S, Brookhart M. J Am Chem Soc. 2012; 134:640-653. [PubMed: 22091749] (b) Cheng C, Brookhart M. J Am Chem Soc. 2012; 134:11304-11307. [PubMed: 22770123]

29. (a) Hanamoto T, Fuchikami T. J Org Chem. 1990; 55:4969-4971.(b) Mohanta PK, Davis TA, Gooch JR, Flowers RA. J Am Chem Soc. 2005; 127:11896-11897. [PubMed: 16117501] (c) Malamakal RM, Hess WR, Davis TA. Org Lett. 2010; 12:2186-2189. [PubMed: 20408600]

30. Stanton GR, Norrby PO, Carroll PJ, Walsh PJ. J Am Chem Soc. 2012; 134:17599-17604. [PubMed: 23003333]

31. Horton DA, Bourne GT, Smythe ML. Chem Rev. 2003; 103:893-930. [PubMed: 12630855]

32. (a) Seganish WM, DeShong P. J Org Chem. 2004; 69:6790-6795. [PubMed: 15387604] (b) Zhang L, Wu J. J Am Chem Soc. 2008; 130:12250-12251. [PubMed: 18715001] (c) Wu X, Li M-L, Wang P-s. J Org Chem. 2014; 79:419-425. [PubMed: 24328038]

33. (a) Lafrance M, Fagnou K. J Am Chem Soc. 2006; 128:16496-16497. [PubMed: 17177387] (b) Yang S, Sun C, Fang Z, Li B, Li Y, Shi Z. Angew Chem, Int Ed. 2008; 47:1473-6.(c) Wen J, Zhang J, Chen SY, Li J, Yu XQ. Angew Chem, Int Ed. 2008; 47:8897-8900.(d) McGlacken GP, Bateman LM. Chem Soc Rev. 2009; 38:2447-2464. [PubMed: 19623360] (e) Phipps RJ, Gaunt MJ. Science. 2009; 323:1593-1597. [PubMed: 19299616] (f) Hachiya H, Hirano K, Satoh T, Miura M. Angew Chem, Int Ed. 2010; 49:2202-2205.(g) Ciana CL, Phipps RJ, Brandt JR, Meyer FM, Gaunt MJ. Angew Chem, Int Ed. 2011; 50:458-462.(h) Funaki K, Kawai H, Sato T, Oi S. Chem Lett. 2011; 40:1050-1052.

34. Schön U, Messinger J, Solodenko W, Kirschning A. Synthesis. 2012; 44:3822-3828. 
a. Prior approaches for transition metal-catalyzed $\mathrm{C}-\mathrm{H}$ silylation of protected phenols (ortho and meta/para)

a1. Directing control: Catalytic method limited efficiency

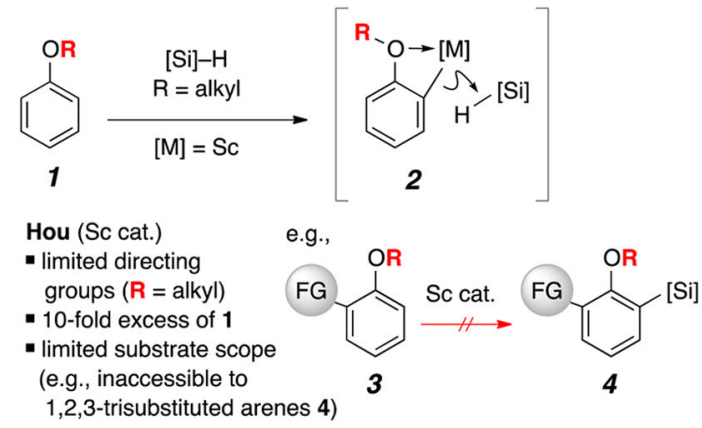

a2. Steric Control: Catalytic method well developed

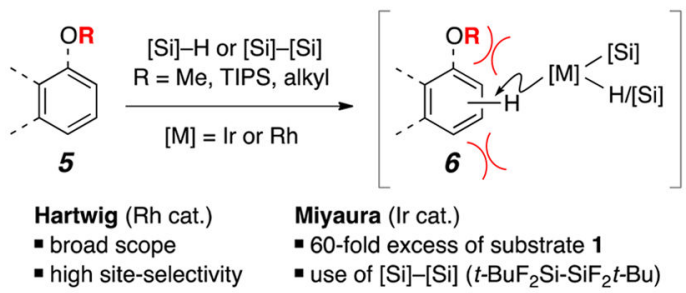

b. This work: Strategy for use of a disubstituted silyl synthon (7) and phenyl acetate (8) for catalytic reductive ortho- $\mathrm{C}-\mathrm{H}$ silylation of phenols using a traceless acetal directing group (DG)

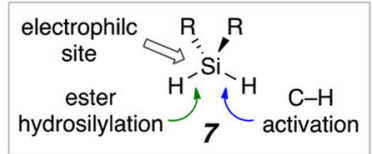

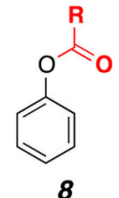

inexpensive and easily installable acetyl DG

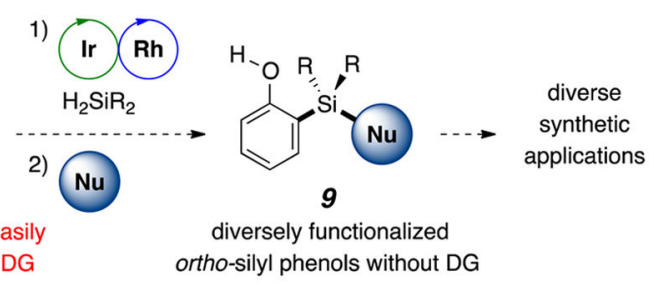

- Proposed reaction mechanism
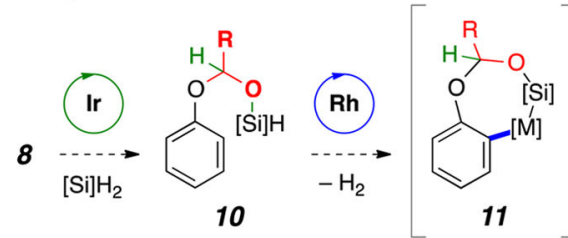

Scheme 1.

Catalytic Site-Selective C-H Silylation of Phenols and Phenol Derivatives 

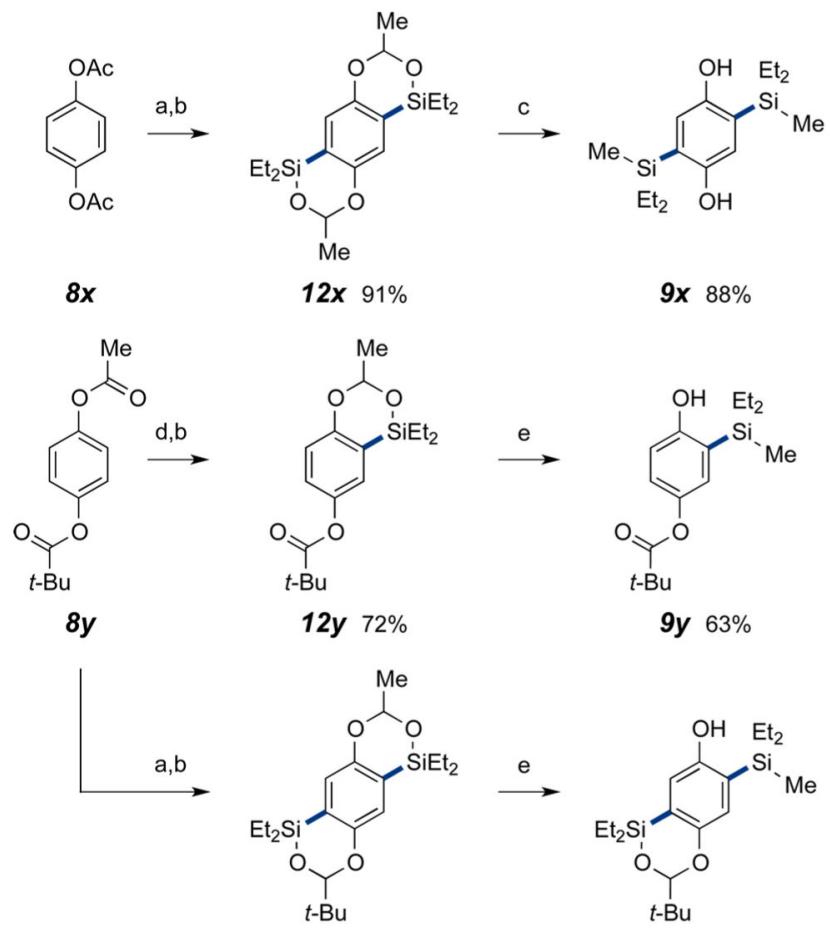

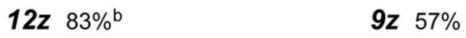

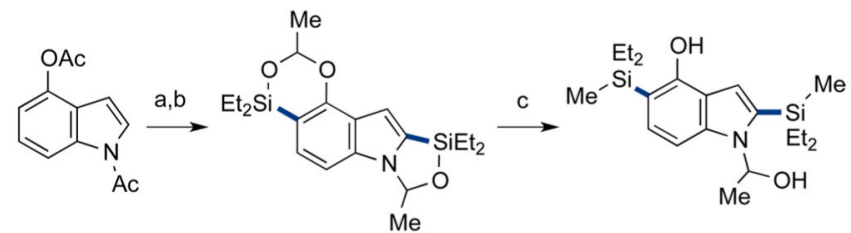

$8 a a$

12aa $71 \%$ b

9aa $38 \%$
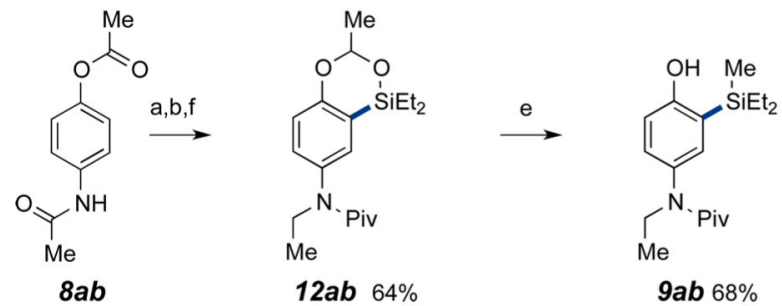

Scheme 2.

Synthesis of Multi-Substituted Arenes via Dual Catalytic Reductive ortho-C-H Silylation of Aromatic Acetates with Traceless Acetal Directing Groups ${ }^{a}$

${ }^{a}$ Conditions: (a) $[\operatorname{Ir}(\mathrm{coe}) \mathrm{Cl}]_{2}(0.5 \mathrm{~mol} \%), \mathrm{H}_{2} \mathrm{SiEt}_{2}$ (4 equiv), $\mathrm{THF}(2 \mathrm{M}), 60{ }^{\circ} \mathrm{C}, 10 \mathrm{~h}$; (b) $[\mathrm{Rh}(\mathrm{nbd}) \mathrm{Cl}]_{2}(1 \mathrm{~mol} \%), \mathrm{P}(4-\mathrm{OMePh})_{3}(6 \mathrm{~mol} \%)$, nbe (4 equiv), THF $(1 \mathrm{M}), 120{ }^{\circ} \mathrm{C}, 30$ min; (c) MeLi (6 equiv), THF, ${ }^{-7}{ }^{\circ} \mathrm{C}$; (d) $[\mathrm{Ir}(\mathrm{coe}) \mathrm{Cl}]_{2}(0.5 \mathrm{~mol} \%), \mathrm{H}_{2} \mathrm{SiEt}_{2}$ (2 equiv), THF ( $2 \mathrm{M}), \mathrm{rt}, 10 \mathrm{~h}$; (e) MeLi ( 3 equiv), THF, $-78^{\circ} \mathrm{C}$; (f) $\mathrm{PivCl}\left(1.5\right.$ equiv), $\mathrm{Et}_{3} \mathrm{~N}$ (2 equiv), $\mathrm{CH}_{2} \mathrm{Cl}_{2}$, rt. 


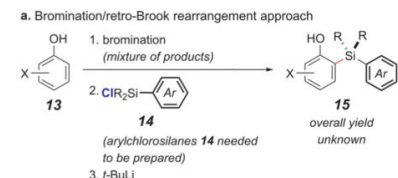$$
\begin{aligned}
& \text { (arylchloreside } \\
& \text { to be prep } \\
& \text { 3. } t \text {-BuLi }
\end{aligned}
$$

b. DoM chlorosilylation/nucleophilic addition approach

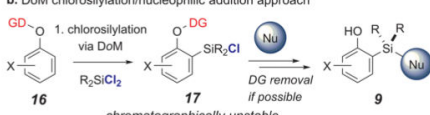

$16 \quad 17$ if possits

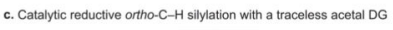

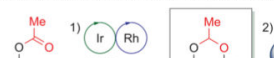

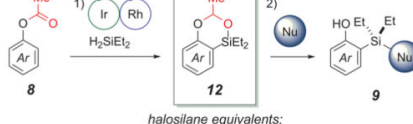

halosilane equivalents:

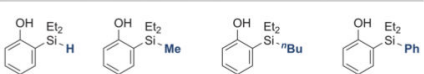

9ac $94 \%$ (LAH) $\quad 9 a 95 \% \quad$ 9ad $98 \% \quad 9 a 090 \%$

$\underbrace{\mathrm{H}_{9} \mathrm{Et}_{2}}_{9 \text { af } 97 \%}$
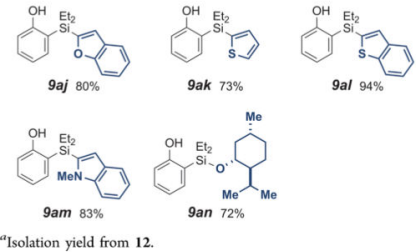

Scheme 3 .

Dioxasilines as Halosilane Equivalents for the Synthesis of Functionalized Silanes ${ }^{a}$ assolation yield from $\mathbf{1 2}$. 


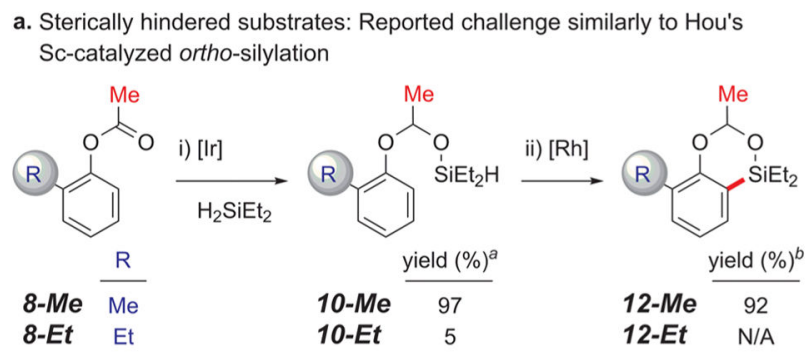

b. Proposed dual activation of iridium silyl hydride by $\alpha$-heteroatomcontaining acetyl group

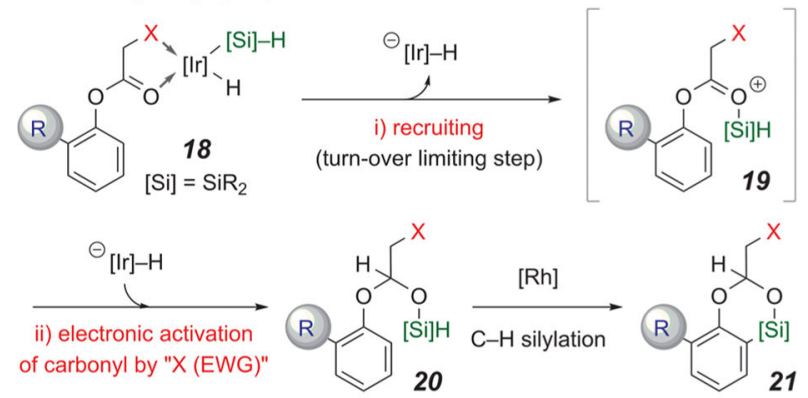

c. $\alpha$-Heteroatom-containing phenyl acetates as formal directing groups

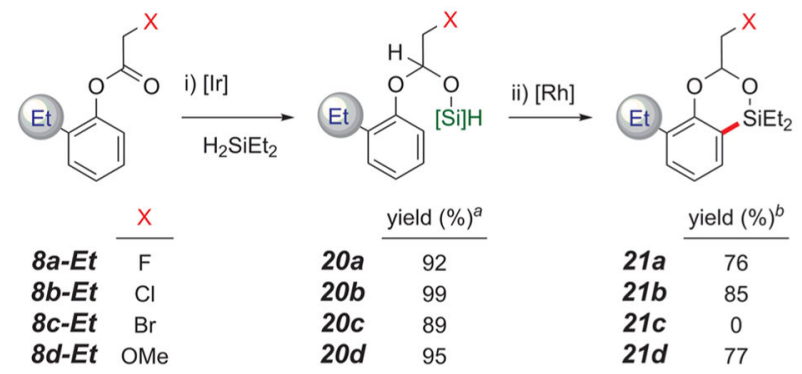

d. Evaluation of other sterically demanding phenyl acetates

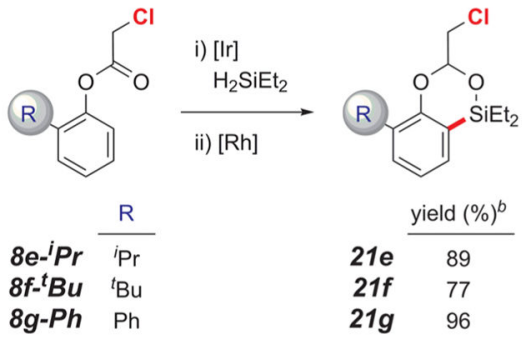

\section{Scheme 4.}

Synthesis of 1,2,3-Trisubstituted Arenes via Catalytic Reductive C-H Silylation of Sterically Hindered Phenyl Acetates: Dual Activation of Iridium Silyl Hydride by an $a$-Chloroacetyl Directing Group ${ }^{a}$

${ }^{a}$ Determined by ${ }^{1} \mathrm{H}$ NMR spectroscopy utilizing an internal standard $\left(\mathrm{CH}_{2} \mathrm{Br}_{2}\right) .{ }^{b}$ Isolated yield (two steps from the corresponding phenyl acetate). 

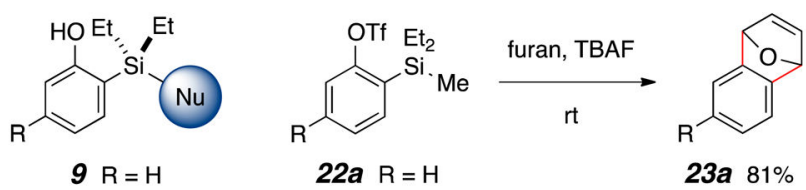

(Scheme 3)

$22 a \mathrm{R}=\mathrm{H}$

$22 b R=F$

23a $81 \%$

$23 b \quad 71 \%$
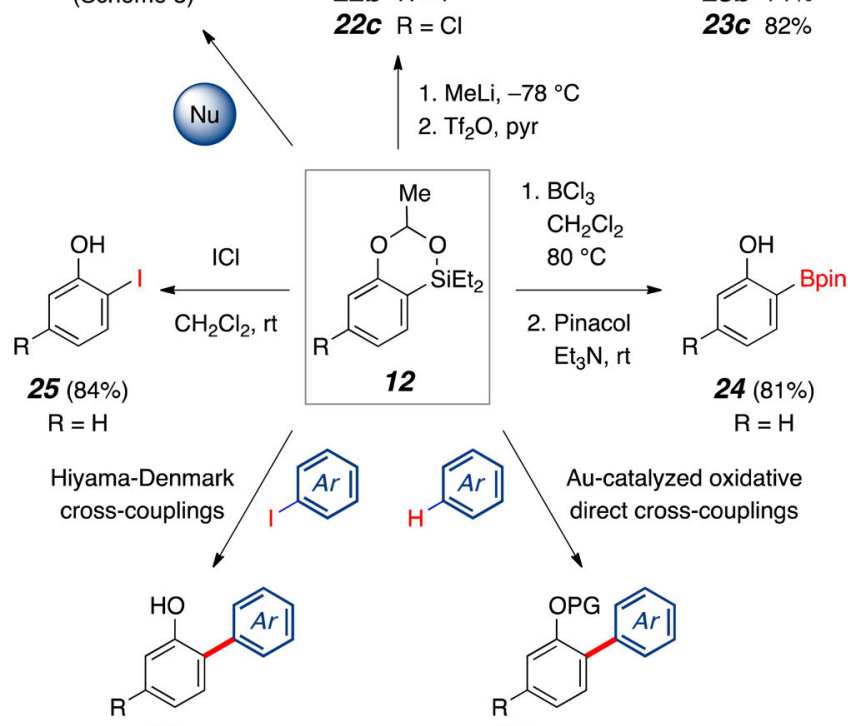

$26 \mathrm{R}=\mathrm{H}$

(Table 2)

$27 \mathrm{PG}=\mathrm{Tf}, \mathrm{Ms}$

(Scheme 7)

Scheme 5.

Synthetic Applications of Benzodioxasilines 


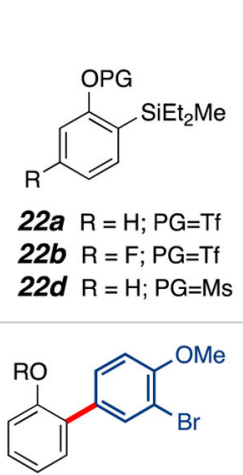

$27 a \mathrm{R}=\mathrm{Tf}(93 \%)$

$27 b \mathrm{R}=\mathrm{Ms}(89 \%)$

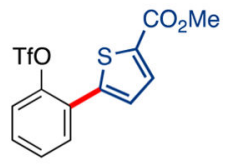

$27 e(92 \%)$

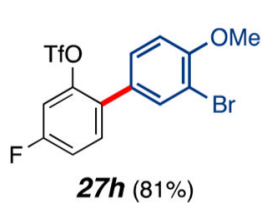

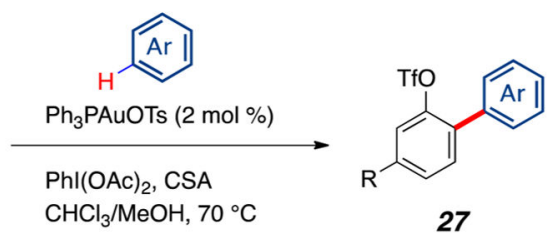

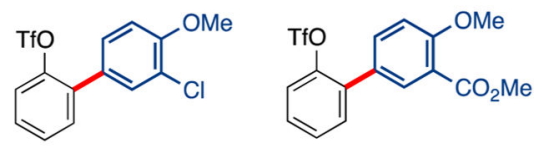

$27 c(76 \%)$

$27 \boldsymbol{d}(71 \%)$

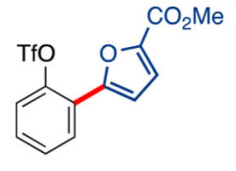

$27 f(43 \%)$

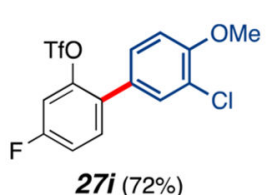

$27 i(72 \%)$
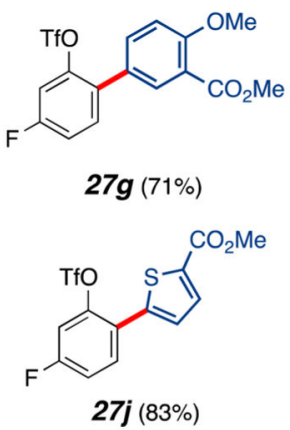

Scheme 6.

Au-Catalyzed Oxidative Direct Cross-Coupling of ortho-Silyl Phenols with Arenes 
a. A sequential desilylative oxidative and Suzuki-Miyaura cross-coupling

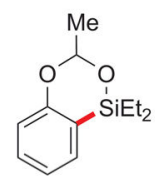

$12 a$

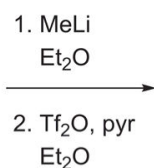

$\mathrm{Et}_{2} \mathrm{O}$

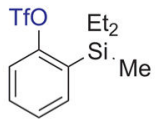

22a

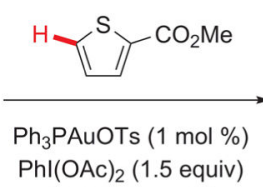

CSA ( 1.3 equiv) $\mathrm{CHCl}_{3} / \mathrm{MeOH}, 70^{\circ} \mathrm{C}$

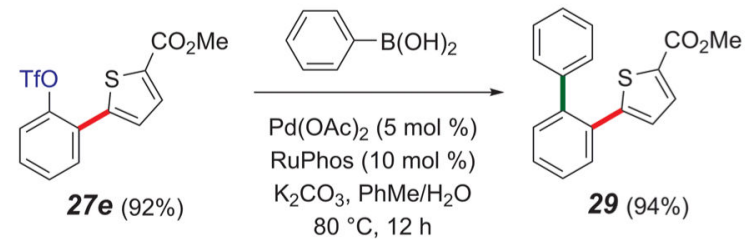

b. A sequential desilylative oxidative and Heck cross-coupling<smiles>CC[Si]c1ccccc1O</smiles>

$22 a$

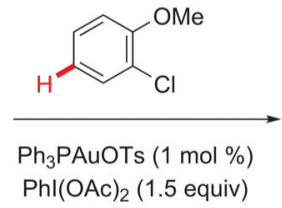
CSA ( 1.3 equiv) $\mathrm{CHCl}_{3} / \mathrm{MeOH}, 70{ }^{\circ} \mathrm{C}$

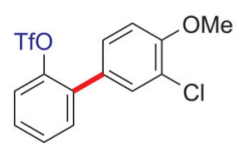

27c $(76 \%)$

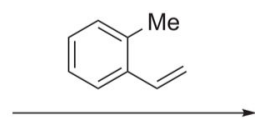

$\mathrm{Pd}(\mathrm{OAc})_{2}(5 \mathrm{~mol} \%)$

dppf (10 mol \%)

${ }^{i} \mathrm{Pr}_{2} \mathrm{NEt}$, THF

$80{ }^{\circ} \mathrm{C}, 12 \mathrm{~h}$

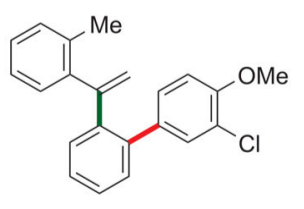

$30(61 \%, \alpha: \beta=5: 1)$

Scheme 7.

Sequential Orthogonal Cross-Couplings of Benzodioxasilines 
a. C2-Silylation of estrone
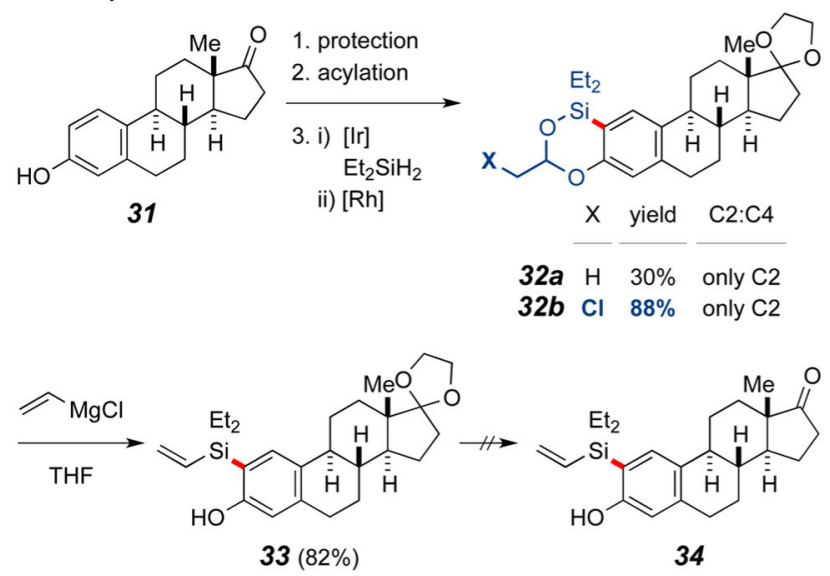

b. C2-Silylation of estradiol
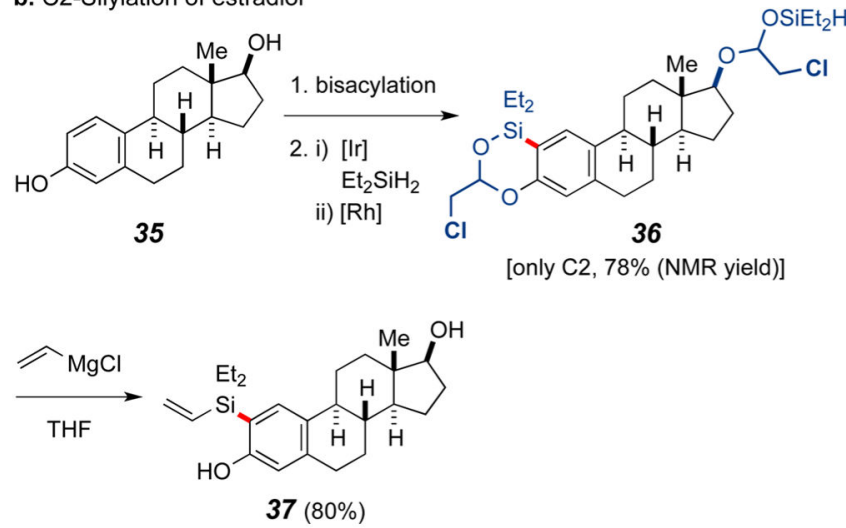

Scheme 8.

Selective C-H Silylation and Ring-Opening Reactions of Estrone and Estradiol 


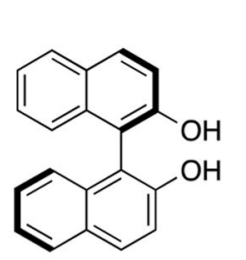

$( \pm)-38$

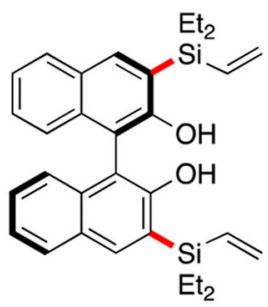

$( \pm)-40(85 \%)$

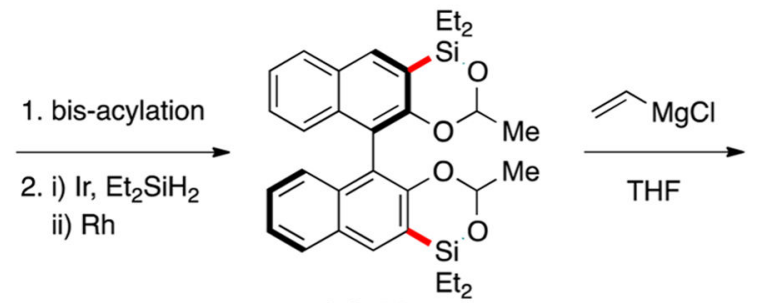

( \pm - -39 (92\%)

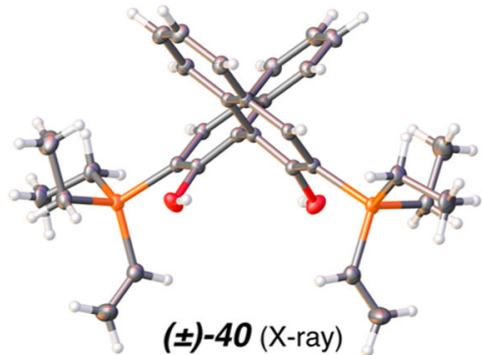

Scheme 9.

3,3'-Bis-Silylation of BINOL 


\section{Table 1}

Catalytic Reductive ortho-C-H Silylation of Phenyl Acetates with a Traceless Acetal Directing Group ${ }^{a}$

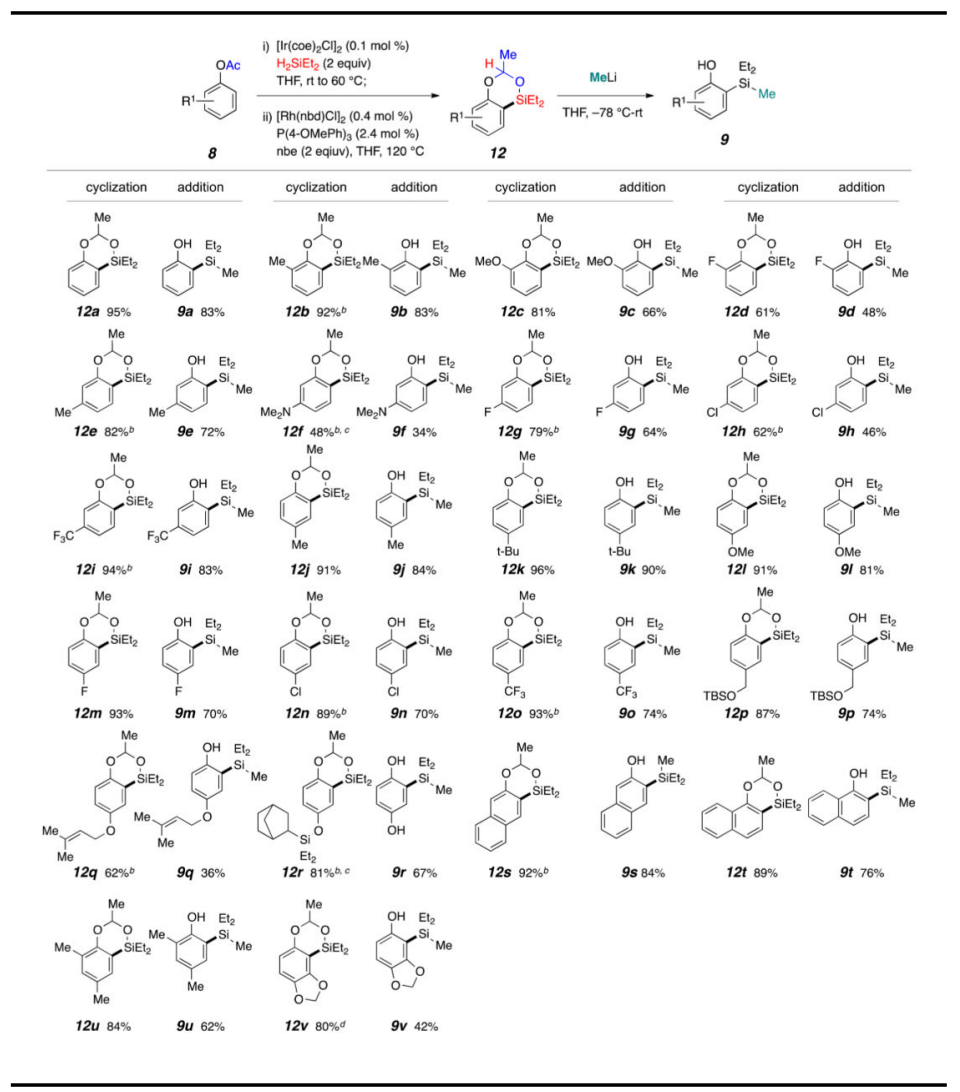

${ }^{a}$ Conditions: phenol acetates 8 ( $\left.1 \mathrm{mmol}\right),\left[\mathrm{Ir}(\mathrm{coe})_{2} \mathrm{Cl}\right]_{2}(0.1 \mathrm{~mol} \%)$, THF $(3.3 \mathrm{M}) ;[\mathrm{Rh}(\mathrm{nbd}) \mathrm{Cl}]_{2}(0.4 \mathrm{~mol} \%), \mathrm{P}(4-\mathrm{OMePh}) 3(2.4 \mathrm{~mol} \%)$, norbornene (2 equiv), $\operatorname{THF}(1 \mathrm{M}), 120^{\circ} \mathrm{C}, 15 \mathrm{~min}$; $\operatorname{MeLi}\left(3\right.$ equiv), $\operatorname{THF}(0.5 \mathrm{M}),{ }^{-} 78^{\circ} \mathrm{C}$.

$b_{\text {Determined by }}{ }^{1} \mathrm{H}$ NMR spectroscopy utilizing an internal standard $\left(\mathrm{CH}_{2} \mathrm{Br} 2\right)$.

$\left.\left.c_{[\mathrm{Ir}(\mathrm{coe})}\right)_{2 \mathrm{Cl}}\right]_{2}(0.5 \mathrm{~mol} \%), \mathrm{H}_{2} \mathrm{SiEt} 2$ (4 equiv); $[\mathrm{Rh}(\mathrm{nbd}) \mathrm{Cl}]_{2}(1 \mathrm{~mol} \%), \mathrm{P}(4-\mathrm{OMePh}) 3(6 \mathrm{~mol} \%), 120^{\circ} \mathrm{C}, 60 \mathrm{~min} ; \mathrm{MeLi}(6$ equiv).

${ }^{d}$ With a 3:1 regioisomeric ratio of $\mathbf{1 2 v}$. 
Table 2

Pd-Catalyzed Hiyama-Denmark Cross-Couplings of Benzodioxasiline ${ }^{a}$

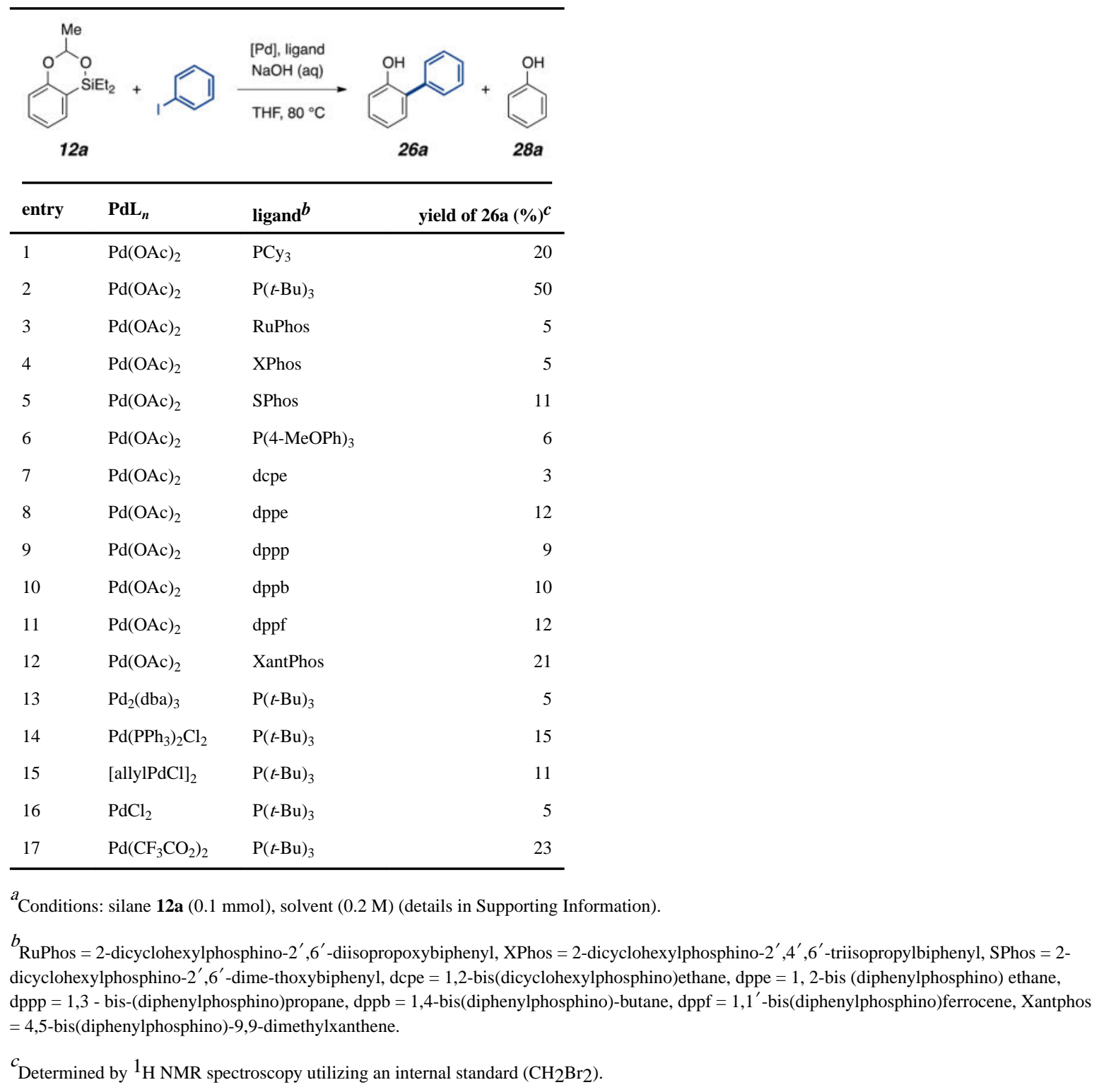

